\title{
The development of a humor styles questionnaire for younger children
}

\begin{abstract}
Despite the adaptation of the humor styles questionnaire for older children a measure suitable for children below the age of eleven was needed. The current research involved three separate studies leading to the creation of the humor styles questionnaire for younger children (HSQY), suitable for those aged 8-11 years. Study one involved the development of a measure to assess aggressive and affiliative humor. Subsequently, study two involved the adaptation of the measure to include all four humor styles, which was administered to children alongside a measure of friendship quality. To provide further validation for the HSQ-Y as a measure, study three involved the administration of the HSQ-Y twice over a three week period and peer reports of the four humor styles. Several measures of psychosocial adjustment were also included. The HSQ-Y was found to be a reliable and valid measure of the four humor styles in children aged 8-11 years. Associations between the humor styles and psychosocial adjustment variables were also found, supporting the discriminant validity of the measure.
\end{abstract}

Keywords: children, humor, humor styles, psychosocial adjustment. 


\section{Introduction}

Research which explores the social and emotional functions of humor has increased in recent years. Work exploring these functions in children however, is noticeably lacking (Martin, 2007). According to McGhee’s (1974) four stage model of humor development, children reach the ultimate stage of development at around the age of seven years; this may therefore be a key age to begin to investigate the important role humor has to play.

As highlighted by Martin (2007), many previously available approaches to measuring humor focused only on the assumption that humor leads to beneficial outcomes. In terms of the ability to measure both positive and negative uses of humor, Martin et al. (2003) developed the humor styles questionnaire for adults (HSQ) proposing four distinguishable, but overlapping, humor styles. The first style of humor, affiliative, was categorised as having the ability to amuse others, tell jokes or say funny things, an example item being, “I don’t have to work very hard at making other people laugh - I seem to be a naturally humorous person”. Secondly, aggressive humor has been described as using humor without consideration of the impact on others, including the use of sarcasm or teasing - "When telling jokes or saying funny things, I am usually not very concerned about how other people are taking it”. Self-enhancing humor was described as a style used by individuals who are able to maintain a humorous outlook on life, particularly when faced with difficult situations. An example item from the humor styles questionnaire is, "It is in my experience that thinking about some amusing aspect of the situation is often a very effective way of coping with problems”. Lastly, self-defeating humor involves an individual's attempts at making others laugh at their own expensive, often by putting themselves down, for example demonstrated by the item, "I will often get carried away in putting myself down if it makes my friends or family laugh”. Self-defeating humor, along with aggressive humor can be considered as maladaptive. Conversely, affiliative and self-enhancing humor can be referred to as adaptive. 
Martin et al. (2003) found that whilst males scored significantly higher on all four styles of humor, this was particularly evident for the maladaptive humor styles.

Martin et al.’s (2003) study also demonstrated important links between the four humor styles and psychosocial adjustment variables. For example, whilst the adaptive humor styles were found to be negatively related to depression and anxiety and positively related to well-being and self-esteem, the opposite was found for self-defeating humor. Martin (2007) stated that using the humor styles questionnaire resulted in stronger correlations between humor styles and psychological adjustment compared to previously available measures. This demonstrates key evidence of its validity and the value of its use over other measures of humor. Subsequently an abundance of further studies utilising the HSQ have also found supporting associations between different styles of humor and psychosocial adjustment variables (e.g. Fitts et al. 2009; Kuiper et al. 2004; Tucker et al. 2013; Yip and Martin, 2006).

Although research exploring the functions of humor in children is limited, some studies have taken place. For example, using peer ratings of humor and social distance, Sherman (1988) found that children rated by their peers as humorous were also rated as less socially distant, a finding also replicated by Warners-Kleverlann et al. (1996). Likewise, Sletta et al. (1995) found that peer reports of humor predicted peer acceptance whilst, children's perceptions of their own humor were also predictive of their perceived social competence. Similarly, using peer and teacher ratings of competence, Masten (1986) found that better humor production and comprehension were associated with better social competence.

Through the use of self-report measures, children's humor research has also focussed on the function of humor as a coping strategy. For example, using the Coping Humor Scale (Martin and Lefcourt 1983), Freiheit et al. (1998) demonstrated a negative relationship between humor and depression in adolescents. Also using the Coping Humor Scale and the 
Children’s Coping Humor Strategy Survey, Führ (2002) found three factors emerging, including using humor to cope, making fun of others and humor to boost the mood. In addition, using the child version of the Multi-Dimensional Sense of Humor Scale (Dowling and Fain 1999), Goodenough and Ford (2005) found that humor may be a useful coping tool for hospitalised children as young as six. However, for Dowling and Fain's (1999) measure, only a two factor solution including coping with humor and humor creation was found. As previously mentioned, Martin et al. (2003) proposed that four main types of humor exist.

Klein and Kuiper (2006) highlighted that the four humor styles model (Martin et al. 2003) had not yet been considered with regard to children. Although Erikson and Feldstein (2007) did use the HSQ to demonstrate relationships between humor styles and depressive symptoms and adjustment in adolescents, unacceptable reliability coefficients were found for the maladaptive humor styles. Klein and Kuiper (2006) suggested that affiliative humor is enjoyed by others and its use can add to children's on-going popularity and provide them with opportunities to acquire an understanding of humor which is deemed socially acceptable. As highlighted by Bergen (1998), humor increases in comfortable settings, providing peer accepted children with opportunities to become skilled in their use of adaptive humor. Klein and Kuiper (2006) proposed that self-enhancing humor can be used to make children appear confident and self-assured. Children may therefore gain a desirable position in their peer group leading to increases in their feelings of self-worth.

In contrast to the adaptive humor styles, Klein and Kuiper (2006) believed that selfdefeating humor can reflect an inner neediness and low self-esteem. They suggested that children may take on board jokes made about them by others and use them in attempts to gain acceptance. Similarly some users of aggressive humor may have a limited ability to understand their peer group and therefore use highly detectable humor which exceeds the 
boundaries of what is considered acceptable. In the long term, these children who lack the ability to use more adaptive styles of humor may therefore be rejected by their peers.

Based on Klein and Kuiper’s (2006) suggestions, Fox et al. (2013) adapted the HSQ to create the child HSQ. The measure was administered alongside several measures of psychosocial adjustment to both primary and secondary aged children. Findings showed a clear four factor structure and all subscales were found to have acceptable internal reliability for children aged 11 years and above. As expected, boys were found to use aggressive forms of humor significantly more than girls. In support of Martin et al.’s (2003) findings, significant associations were also found between the humor styles and psychosocial adjustment variables. For example, affiliative humor was found to be positively related to self-perceived social competence and self-worth. Self-defeating humor on the other hand was found to be negatively related to self-perceived social competence and self-worth and positively related to both anxiety and depression.

To investigate causality, Fox et al. (2015) conducted a longitudinal study which found bi-directional relationships between humor styles and adjustment. Self-defeating humor at time one was found to predict an increase in loneliness and depression and a decrease in selfesteem at time two. In addition, depressive symptoms predicted an increase in the use of selfdefeating humor over time, indicating that these may represent a problematic spiral of thoughts and behaviours. Fox et al. (2015) suggested that children may get caught in a vicious cycle when using this sort of humor with one problem exacerbating the other. In contrast, self-esteem predicted an increase in use of affiliative humor over time.

Although the child HSQ (Fox et al. 2013) was found to be an appropriate measure of humor for secondary aged children above the age of eleven, it was not found to be suitable for those below the age of eleven. This means that the period of middle childhood which was highlighted by Klein and Kuiper (2006) as being particularly important to furthering our 
understanding of children's peer relationships, remains largely uninvestigated. Fox et al. (2013) suggested that a two factor structure maybe a better reflection of how younger children use humor and that self-enhancing and self-defeating humor may develop at a later stage, most likely as they are more reliant on cognitive processes. In addition, Fox et al. (2013) questioned whether younger children are sufficiently aware of their own humor use. It was also recommended that peer reports of humor should be utilised with younger children as socially desirable responding may be more likely. Although teacher reports could also be used, it may be that teachers are unaware of certain behaviours. For example, teachers may view humorous behaviours as disruptive, meaning that children begin to use humor less in their presence (Damico and Purkey 1978; Fabrizi and Polio 1987).

Very little research has addressed how different styles of humor develop and this has been further hampered by the lack of a suitable measure to investigate the potential presence of humor styles in an age group younger than eleven. Using a twin study, Vernon et al. (2008) found that whilst the adaptive humor styles were more attributable to genetic factors, the maladaptive humor styles were more attributable to environmental factors. The role of environmental factors in the development of humor styles suggests that they may develop at different rates. To investigate this further, being able to assess humor in children at the earliest possible point would be beneficial.

In support of the presence of self-defeating and self-enhancing humor in this agegroup, children have been found to display maladaptive explanatory styles which include self-derogatory attributions often linked with depressive symptoms (Nolen-Hoeksema et al. 1991). The question is when children begin to externalise these thoughts to make other people laugh; it is likely that this comes with experience. Thus, it is possible that selfdefeating humor develops slightly later than the other forms. Also, before they reach this 
stage, children may not recognise the more complex concepts associated with self-defeating humor.

It has long been theorised that children use humor for emotional mastery and as a way of dealing with various challenges imposed on them during socialisation (e.g. McGhee 1979). Masten (1986) for example, cited observations which found evidence that children do use humor to cope with fear and anxiety. Research by Altshuler and Ruble (1983) showed age related increases in the ability to manage emotions in uncontrollable situations using more cognitive as opposed to behavioural strategies (e.g. cognitive distraction). They cited evidence to suggest that younger children are capable of recognising that thoughts can be manipulated (i.e. they understand the concept) and that with age, they come to learn how to use these strategies more effectively to manage emotions.

The current research endeavoured to adapt the child HSQ for use with primary aged children. The assessment of humor styles in younger children has much to contribute to our understanding of how humor develops from childhood to adolescence. Initially for study one, based on Fox et al.’s (2013) suggestions, the child HSQ was adapted to include just affiliative and aggressive humor. For study two, the measure was again adapted to include all four humor styles and administered alongside a measure of friendship quality as suggested by Fox et al. (2013). For study three, to provide further validation for the measure, use of peer reports of humor were employed alongside self-reports and the HSQ-Y was administered twice to assess test re-test reliability. Moreover, further measures of psychosocial adjustment were administered to demonstrate whether the associations found in adults and older children can be replicated with the primary age-group.

Based on the literature, a number of predictions for the current research were made. Firstly, based on the findings of Martin et al. (2003) and Fox et al. (2013), it was predicted that males would use the maladaptive humor styles more than females. As discussed, 
children's humor styles may still be in developing. It was therefore predicted that there would also be year group differences in the use of different humor styles. In terms of psychosocial adjustment, based on the suggestions of Klein and Kuiper (2006) and the findings of Fox et al. (2013), it was predicted that the adaptive humor styles would be positively associated with psychosocial adjustment, whilst the maladaptive humor styles would be negatively associated.

\section{Study One: Method}

\subsection{Participants}

250 children were recruited from two UK primary schools. The participants were aged 8-11 years and in school years 4, 5 and 6 with a mean age of 9.27 years $(\mathrm{SD}=.91)$ consisting of 121 boys and 129 girls. Parental consent was gained using the opt-out method.

\subsection{Materials}

The younger children's humor styles questionnaire (HSQ-Y), which was developed by the researchers, was used to measure aggressive and affiliative humor. The questionnaire contained sixteen items - eight items measuring affiliative humor and eight items measuring aggressive humor. The questionnaire was created by simplifying items measuring affiliative and aggressive humor from Fox et al.’s (2013) humor styles questionnaire for children and the original adult HSQ (Martin et al. 2003). The simplified items were considered to have a more appropriate readability for younger children (Flesch reading ease score of the items = 84.9, US grade level = 3.6, 8-9 years of age). No items were negatively worded, due to previous research suggesting that younger children may not be able to comprehend negatively worded items (Marsh 1986). Items were measured on a four point response scale from, $1=$ 
'not at all like me', 2 = 'not like me', 3 = 'a bit like me' and 4 = 'a lot like me'. This was thought to be more appropriate for younger children than the Fox et al. (2013) scale which ranged from ‘strongly disagree' to ‘strongly agree’. A four point response scale as used by Fox et al. (2013) was chosen due to children's tendency to repeatedly opt for a neutral midpoint response should one be available (Borgers et al. 2004). A mean score for each humor style was calculated for analysis.

\subsection{Procedure}

Following the development of materials, ethical approval was granted and two local primary school head teachers were approached by email and agreed to take part in the research. During sessions of data collection, which were conducted on a whole class basis, the researchers used a standardised preamble to ensure instructions were delivered to children consistently. It was stressed to the children that participation was their choice and that it was acceptable for them to withdraw at any point. They were also reassured that their answers would be kept confidential. Each questionnaire item was then read aloud. Following completion of the questionnaire, the children were fully debriefed.

\section{Results}

\subsection{Reliability analysis}

To improve the overall reliability of the questionnaire and to highlight items to be deleted, the reliability of the sixteen items on the HSQ-Y were reviewed along with the mean (and SD) for all items. All items for both subscales were found to have acceptable levels of reliability. The items found to have the most extreme scores for their sub-scale and a lack of variation highlighted by their means (and SDs) were deleted, as it was suggested most participants 
were disagreeing (or agreeing) with that item. Deletion of one affiliative item, "I laugh and joke a lot with my closest friends” and one aggressive item, “If someone makes a mistake I will tease them about it” followed as these items were found to have the highest or lowest mean scores, 'affiliative8' $=3.82$ and 'aggressive1' $=1.53$. A final fourteen items remained with the Cronbach's alphas for both the affiliative $(\alpha=.84)$ and aggressive ( $\alpha=.86)$ subscales being above the .70 level considered satisfactory.

\subsection{Factor analysis}

The fourteen HSQ-Y items were entered into a principal components analysis. Suitability of the data for factor analysis was assessed demonstrating a Kaiser-Meyer-Olkin score of .85 and Bartlett's test of sphericity was significant at $p<.001$. Principal components analysis revealed that two components had eigenvalues greater than 1, explaining a total of $53.08 \%$ of the variance. A varimax rotation was used to aid interpretation. Table 1 presents the factor loadings, showing a clear two factor structure with items loading highly with associated items and no cross-loadings.

Table 1 here

\section{Discussion}

Following the development of the child humor styles questionnaire (Fox et al. 2013), the measure was adapted for use with children below the age of eleven. Initially just the affiliative and aggressive subscales were included for this age group. Both the affiliative and aggressive subscales were found to have acceptable levels of reliability and a clear two factor 
structure emerged. However further work was needed to evaluate the feasibility of including all four humor styles.

\section{Study Two: Method}

\subsection{Participants}

161 children were recruited from two UK primary schools. Participants were aged 8-11 years with a mean age of 9.70 years $(S D=.98)$, were in school years 4,5 and 6 and the sample consisted of 78 boys and 83 girls.

\subsection{Materials}

Paired interviews were conducted with children aged 8-11 years to explore the possibility of measuring self-defeating and self-enhancing humor. ${ }^{1}$ Most of the children seemed to understand the concepts and there was evidence that some children used both self-enhancing and self-defeating humor. In addition to this, the questions used during the interviews were understood sufficiently by the children. These questions were again simplified from items used to assess self-enhancing and self-defeating humor in the child and adult HSQs (Fox et al. 2013; Martin et al. 2003). This being the case, it was concluded that the same questions should be adapted for use in the HSQ-Y, to be used with a larger sample. The HSQ-Y as used in study one was adapted to include twenty six items - seven items measuring affiliative humor, seven items measuring aggressive humor, six items measuring self-enhancing humor and six measuring self-defeating humor (Flesch reading ease score of the adapted HSQ-Y = 84.9, US grade level = 3.6, age 8-9 years). Seven affiliative and seven aggressive items were included with the intent of reducing the number of items, with the eventual aim of achieving

\footnotetext{
${ }^{1}$ Reported in James and Fox (2016)
} 
a measure with a more appropriate twenty four or fewer items for younger children. Although for self-enhancing and self-defeating a larger pool of items may have been desirable, formulating a greater number of items measuring these humor styles accessible to children proved difficult.

Selected subscales from Bukowski et al.’s (1994) Friendship Qualities Scale were used to assess children's beliefs about their relationship with a close friend. The two subscales selected included Closeness and Conflict to explore both the positive and negative aspects of friendships. The Closeness subscale, which included 5 items, required children to think about a close friend and decide whether a statement was 'not at all true', 'not true', 'a bit true' or 'very true' (1-4) for their friendship. The response scale was altered from the five point scale used by Bukowski et al. (1994), again to avoid the potential overuse of a midpoint response (Borgers et al. 2004). The Conflict subscale contained 4 items and used the same response scale. No items were negatively worded or required reverse coding. Children received the highest score for selecting 'very true' and the lowest score for selecting 'not at all true'. In the current study, the reliability coefficients for the two subscales were as follows: Conflict $=.81$, Closeness $=.66$, suggesting that the findings for the closeness subscale should be treated with some level of caution. Mean scores for both Closeness and Conflict were calculated.

\subsection{Procedure}

The same procedures employed in study one were used for recruitment of schools and data collection. 


\section{Results}

\subsection{Reliability analysis}

The reliability of the twenty six items on the HSQ-Y was reviewed along with the means (and SDs) for all items. This was conducted with a view to improving the overall reliability of the questionnaire and to highlight items to be considered for deletion. Table 2 shows Cronbach’s alphas for all subscales.

Table 2 here

All items for the affiliative, aggressive and self-enhancing subscales were found to have acceptable levels of reliability being above the .70 level considered satisfactory. Further work however involved considering deletion of certain items particularly for the affiliative and aggressive subscales which both had 7 items. For example, the item 'affiliative 6' "I can make my friends and family laugh" was found to have the most extreme score and lack of variation of its subscale as shown by its mean (and SD). Its high mean score of 3.65 suggested that most participants were agreeing with this item and it was therefore removed. For the aggressive subscale, deletion of one item 'aggressive 1' "When other people are laughing at someone, I will join in” increased the reliability of the subscale only very slightly to .87. The item 'aggressive 7' “If I don't like someone, I make fun of them” however, had the lowest, most extreme mean score of 1.87 suggesting most children disagreed with this item and it was therefore removed.

In comparison, the self-defeating sub-scale was found to have unacceptably low reliability. The deletion of 'self-defeating 5' "I try to get people to like me by talking about 
things I'm not very good at in a funny way" and 'self-defeating 6' "If I am feeling unhappy, I joke around so my friends don’t know how I am feeling” increased the reliability very slightly to .62. For friendship quality, conflict was found to have acceptable levels of reliability whilst closeness was found to be below the .70 level considered satisfactory.

\subsection{Factor analysis}

As a starting point, all twenty two HSQ-Y items (6 affiliative, 6 aggressive, 6 self-enhancing, 4 self-defeating) were entered into a principal components analysis (PCA). Suitability of the data for factor analysis was assessed with a Kaiser-Meyer-Olkin score of .77 exceeding the recommended value of .6 and Bartlett's test of sphericity was significant at $p<.001$. Inspection of the correlation matrix also revealed the presence of a number of coefficients of .3 and above. Principal components analysis revealed that six components had eigenvalues greater than 1 , explaining a total of $64.73 \%$ of the variance. An inspection of the scree plot revealed a break after the forth component. It was therefore decided to retain four components for further analysis, with the solution explaining a total of $54.89 \%$ of the variance. A varimax rotation was used to aid interpretation. Table 3 presents the factor loadings, showing a four factor structure with many items loading strongly with associated items. Cross-loading occurred on two occasions although the items still loaded most strongly with associated items. The interpretation of the four components is consistent with the four humor styles. Items and their corresponding numbers do vary from study to study due to the development of the HSQ-Y.

Table 3 here 


\subsection{Intercorrelations}

Table 4 shows the correlations between all of the variables included in the study. As expected, significant positive correlations were found between both aggressive and selfdefeating humor and conflict in friendship, whilst a significant negative correlation was found between conflict and self-enhancing humor. No significant negative correlation was found with conflict for affiliative humor. For closeness in friendship, again unexpectedly, no significant positive correlations were found for the adaptive humor styles but closeness was as expected, found to be negatively associated with aggressive humor. In terms of associations between the different humor styles, affiliative humor was found to be positively correlated with all other humor styles, whilst self-defeating humor was also found to be positively associated with both aggressive and self-enhancing humor.

Table 4 here

\section{Discussion}

The HSQ-Y was adapted to include all four humor styles following qualitative research indicating use of self-enhancing and self-defeating humor in some children (James and Fox 2016). Whilst the first three subscales of the HSQ-Y were found to have acceptable levels of reliability, reliability of the self-defeating subscale was found to be lower, demonstrating the need for further work primarily involving the development of two new self-defeating items. In terms of friendship quality, several significant associations with humor styles were discovered lending support to previous research and suggesting that humor is associated with adjustment problems in children even as young as eight. Following these results, subsequent work was conducted to examine further associations between humor styles and psychosocial 
adjustment. In addition, to provide further validation for the HSQ-Y as a measure, peer reports were gathered.

\section{Study Three: Method}

\subsection{Participants}

225 children were recruited from one large primary school in the South of England.

Participants were aged 8-11 years with a mean age of 9.87 years $(\mathrm{SD}=0.92)$, were in school years 4, 5 and 6 and the sample consisted of 116 males and 109 females. Parental consent was gained using an opt-out method.

\subsection{Materials}

The HSQ-Y was adapted following reliability analysis in the previous study, to include two new self-defeating items to form the twenty four item HSQ-Y - six measuring each of the four humor styles (Flesch reading ease score of the adapted HSQ-Y = 84.9, US grade level $=3.6$, age 8-9 years). These new items were again developed by simplifying items from the child and adult HSQs (Fox et al. 2013; Martin et al. 2003).

The four item self-report Loneliness and Social Satisfaction scale (Asher et al. 1984; Rotenberg et al. 2005) was used as a measure of children’s psychosocial adjustment. The subscale included four items using the same four point response scale used for the HSQ-Y again to avoid the potential overuse of a mid-point response (Borgers et al. 2004). No items were negatively worded or required reverse coding. Children received the highest score for selecting 'a lot like me' and the lowest score for selecting 'not at all like me' (1-4). In the 
current study, a reliability coefficient of $\alpha=.89$ was found. A mean score for loneliness was calculated.

Harter’s (1985) measures of children’s self-perceived social competence and global self-worth were used to assess children's beliefs about their own social capabilities and feelings about themselves. Each measure contained six items in which participants were required to decide which of two statements was most like them. Children were then required to decide whether the statement they had chosen was 'sort of true' for them, or 'really true' for them. Children received the lowest score for responding 'really true' to the statement that displayed lower social competence/self-worth and the highest score for responding 'really true' to the statement that displayed higher social competence/self-worth (1-4). For both subscales, three items required reverse coding. The reliability coefficients for the two subscales in the current study were as follows: Global self-worth $\alpha=.73$, Self-perceived social competence $\alpha=.81$. Mean scores for self-perceived social competence and global selfworth were calculated.

For the first peer report task, children were required to tick the names of all of their classmates who used each of the four humor styles. Unlimited nominations were used based on concerns that children may not follow instructions if nominations were limited to a certain number of classmates (Jones et al., 2013). Children were provided with a list of the names of all children in their class taking part in the research. Males and females were included in the same list and names were presented in a random order (Poulin and Dishion 2008). The four humor styles were represented by a statement based on items from the HSQ-Y found to have the highest item total correlations in study two. In addition, the statement 'They are one of my closest friends’ was included requiring children to tick the names of children they considered to be a friend (see Parker and Asher 1993). For the humor and closest friend nominations a percentage score was calculated for each child due to the varying numbers of 
children in each class. This involved dividing the number of nominations for each child by the number of children providing nominations minus one and multiplying the figure by one hundred.

To assess peer acceptance, again a list of the names of all participating children in a class were included following the instruction for children to circle how much they would like to play with each of their classmates (see Singleton and Asher 1977). Children were required to respond on a five point scale from 'I wouldn't really like to play with them at all' to 'I would like to play with them very much’ (1-5). An average peer acceptance score was calculated for each child by dividing the sum of ratings by the number of participating children minus one.

\subsection{Procedure}

The same procedures employed in study one and study two were used for the recruitment of schools and data collection. Due to the number of measures included in the research and to assess test re-test reliability, data collection took place over two sessions, three weeks apart. As children were required to write their names on their questionnaires so that responses from each session could be matched, confidentiality was emphasised. During the first session of data collection, children completed the HSQ-Y and the measures of loneliness, self-perceived social competence and global self-worth.

During the second session of data collection, children were reminded of all the information they had been given at session one. In the current study, all children who had participated in the first session decided to take part in the second session. The HSQ-Y was administered during each session so that test re-test reliability could be assessed. Before moving onto the peer report section of the questionnaire it was gently discussed that children should not share their answers with other children so that their feelings could be kept private 
(Jones et al., 2013). Following completion of the measures in the second session, the aims of the project were explained to the children. If questions arose after the session children were urged to speak to a teacher or parent.

\section{Results}

\subsection{Reliability analysis}

The reliability of the 24 HSQ-Y items was reviewed. All items for all subscales were found to have acceptable reliability being above the .70 level considered satisfactory (Affiliative $\alpha$ $=.90$, Aggressive $\alpha=.86$, Self-enhancing $\alpha=.78$, Self-defeating $\alpha=.70$ ).

\subsection{Test re-test reliability}

Test re-test correlations were found to be either moderate or high. Portney and Watkins’ (2000) guidelines state that correlation coefficients between .5 and .8 suggest moderate test re-test reliability, whilst correlation coefficients greater than .8 suggest high test re-test reliability (Affiliative $=.81$, Aggressive $=.81$, Self-enhancing $=.68$, Self-defeating $=.73$ ) .

\subsection{Factor analysis}

All twenty four HSQ-Y items were entered into a principal components analysis (PCA). Suitability of the data for factor analysis was assessed with a Kaiser-Meyer-Olkin score of .84 exceeding the recommended value of .6 and Bartlett's test of sphericity was significant at $p<.001$. Inspection of the correlation matrix also revealed the presence of a number of coefficients of .3 and above. Principal components analysis revealed that five components had eigenvalues greater than 1, explaining a total of $59.26 \%$ of the variance. An inspection of the scree plot revealed a break after the forth component. It was therefore decided to retain 
four components for further analysis, with the solution explaining a total of $54.54 \%$ of the variance. A varimax rotation was used to aid interpretation. Table 5 presents the factor loadings, showing a four factor structure with many items loading strongly with associated items. Cross-loading occurred on three occasions although the items still loaded most strongly with associated items. The interpretation of the four components is consistent with the four humor styles.

Table 5 here

\subsection{Confirmatory factor analysis}

Confirmatory factor analysis (using AMOS 21.0) was used to test the proposed four-factor structure of the scale with $N=225$. When it came to analysing the data using CFA, a Full Information Maximum Likelihood was used in the analyses to deal with missing data. Regression weights for one item on each scale were arbitrarily set at 1 . The four factors (as latent variables) were assumed to covary and this was taken into account in the model. The correlations ranged from -.02 to .59 and the standardised regression weights ranged from .23 to .89, see Table 6 for factor loadings. The results indicated an adequate fit to the data, with CMIN/DF values being under 3-4, CFI being above .90 (Bentler 1992) and RMSEA being below .06 (Hu and Bentler 1999). Only the loading of SD2 was found to be lower at below .3 $(\mathrm{CMIN} / \mathrm{DF}=1.72, \mathrm{CFI}=.907, \mathrm{RMSEA}=.057)$. The four factor model identified using exploratory factor analysis was confirmed.

Table 6 here 


\subsection{Multiple groups analysis}

Analysis was conducted to assess whether model parameters were equivalent for males and females. Two models were therefore compared. The first model was an unconstrained model in which factor loadings were allowed to vary across males and females. The second model constrained the factor loadings to be equal across males and females. If the fit of the constrained model is significantly worse than that of the unconstrained model, using chisquare as an indicator, then it should be concluded that effects differ among groups. Using the same approach further analysis was then conducted to assess whether model parameters were equivalent for the three year groups. For males and females, there was no significant loss of fit between the unconstrained and constrained model indicating that the groups did not differ $(\Delta \chi 2=25.84, d f=20, p>.05)$. This was also the case for the three year groups $(\Delta \chi 2=$ 34.96, $d f=40, p>.05)$.

\subsection{Correspondence between self and peer reports of humor}

In terms of associations between self and peer reports of the four humor styles, significant positive associations were found between self and peer reports of affiliative humor $r(203)=$ $.38, p<.001$, aggressive humor $r(195)=.47, p<.001$ and self-defeating humor $r(198)=$ $.29, p<.001$. The positive association between peer and self-reports of self-enhancing humor was not significant $r(199)=.12, p>.05$.

\subsection{Intercorrelations}

Table 7 shows the correlations between the variables included in the study. As expected both adaptive humor styles were found to be positively correlated with global self-worth and selfperceived social competence and negatively correlated with loneliness. They were also found to be positively correlated with peer acceptance and number of mutual friendships, although 
the association between self-enhancing humor and mutual friendships was only approaching significance. Contrary to expectations a significant positive association was found between self-reports of aggressive humor and self-perceived social competence. Unexpectedly, no significant correlations were found between self-defeating humor and any of the psychosocial adjustment variables. In terms of associations between the different humor styles, affiliative humor was found to be significantly positively correlated with all other styles of humor. In addition, significant positive correlations were found between self-defeating and selfenhancing humor and also between self-defeating and aggressive humor.

Table 7 here

\subsection{Gender and year group differences}

Due to the number of variables, gender and year group differences were examined using a 2 (gender) x 3 (year group) MANOVA taking into account all dependent variables; see Table 8 for means (and SDs). For the different humor styles, analyses revealed a significant main effect of gender on both maladaptive humor styles in that boys used more aggressive and self-defeating humor than females, $F(1,157)=17.12, p<.001, \mathrm{y}^{2} \mathrm{p}=.10 ; F(1,157)=5.15, p$ $<.05, \mathrm{y}^{2} \mathrm{p}=.03$. No significant year group effects were found for self-reported use of the four humor styles. A significant interaction effect was found for self-enhancing humor, $F(2,157)=4.55, p<.05, \mathrm{y}^{2} \mathrm{p}=.06$. Simple effects analysis revealed that year four females used self-enhancing humor significantly more than year four males, $F(1,209)=4.91, p<.05$, $\mathrm{y}^{2} \mathrm{p}=.02$

Table 8 here 


\section{Discussion}

In terms of the development of a reliable and valid measure of humor styles in younger children, the HSQ-Y was found to have acceptable levels of reliability for all subscales with a clear four factor structure being apparent. Findings demonstrated adequate test re-test reliability and agreement was found between self and peer reports for three of the four humor styles. Delivery of the measure alongside several psychosocial adjustment variables highlighted a number of important associations between psychological well-being, social adjustment and humor styles in younger children, which we discuss below.

\section{General discussion}

Following the development of the child HSQ, Fox et al. (2013) stated that work was required to develop a measure of the four humor styles suitable for younger, primary-school aged children. Following the completion of three studies, a reliable and valid measure for this age group has been created - the HSQ-Y. As well as the development of a new measure, the studies have also highlighted the presence of a number of important associations between humor and psychosocial adjustment in this age group.

In terms of associations between the adaptive humor styles and psychosocial adjustment variables, affiliative humor was found to be positively correlated with global selfworth, self-perceived social competence, peer acceptance and number of friends, and negatively correlated with loneliness. These findings are supportive of a wealth of research with adults which has found associations between affiliative humor and psychosocial adjustment (e.g. Kuiper et al. 2004). They are also supportive of Fox et al.’s (2013) work with older children which found positive associations between affiliative humor, social competence and global self-worth. Klein and Kuiper (2006) believed that affiliative humor is enjoyed and valued by others and could therefore add to children's on-going acceptance and 
popularity within their peer group. Moreover, being humorous is seen as a highly desirable characteristic in a friend (Sprecher and Regan 2002) which may explain why users of affiliative humor have a greater number of friends. In turn, having many friends and being liked by peers may lead to less feelings of loneliness and greater feelings of self-worth.

For self-enhancing humor, the same pattern of findings as with affiliative humor was evident for global self-worth, self-perceived competence, loneliness, peer acceptance and number of friends, whilst a negative association was also found with friendship conflict in study two. Martin et al. (2003) believed that self-enhancing humor is inversely related to negative emotions and positively related to psychological well-being. As discussed, selfenhancing humor involves possessing a humorous outlook, having an ability to maintain a humorous perspective even in the face of difficulty and also the use of humor as a coping mechanism. The current findings therefore demonstrate that the benefits of this humor style on psychosocial adjustment may be very much present in children as young as eight. Klein and Kuiper (2006) stated that peer accepted children may use self-enhancing humor to display confidence and self-assurance leading to them achieving a desirable position within their peer group. Considering the positive, adaptive nature of self-enhancing humor, it is unsurprising that this type of humor is related to friendship.

In terms of friendship quality, aggressive humor was found to be negatively related to closeness and positively related to conflict. These findings offer support to previous findings such as Yip and Martin (2006), who suggested that maladaptive humor styles can be associated with social skills difficulties such as trouble perceiving others' emotions, which could make conflict more likely. It can be argued that use of aggressive humor may result in boundaries of what is considered acceptable being crossed, which could in turn lead to disagreements. Unexpectedly, positive associations were not found between closeness in friendship and the adaptive humor styles. This could however be due to the reliability of the 
closeness subscale being lower. In addition, it should also be noted that the sample size for study two was smaller compared to studies one and three.

Contrary to expectations, a positive association was found between aggressive humor and self-perceived social competence. Fox et al. (2013) also found a positive association between aggressive humor and social competence in boys. They argued however that selfperceived social competence is a measure of thoughts about the self and not a measure of a child's status. In addition, the impact of aggressive humor on relationships could be more long term. As Martin et al. (2003) stated, excessive use of aggressive humor has a tendency to harm important relationships, which suggests that further work could assess the impact of aggressive humor over a longer time frame. It could also be that some users of aggressive humor may have a distorted perception of their social status.

The findings suggest that children of this age do use self-defeating humor. As noted previously, children have been found to display self-derogatory attributions often linked with depressive symptoms (Nolen-Hoeksema et al. 1991). Unexpectedly, for self-defeating humor, only a significant positive correlation with conflict was found in study two. Fox et al. (2013) did however find significant associations between self-defeating humor and psychosocial adjustment in older children. It could therefore be argued that the potentially negative effects of self-defeating humor only begin to emerge later. If children have only recently begun to use self-defeating humor at the age of eight, it seems reasonable that it may take time for negative impacts to become apparent. This may also help to explain why it may have been more challenging to develop items to obtain an acceptable alpha value for the self-defeating subscale. As found by James and Fox (2016), there were individual differences in children’s understanding of self-defeating humor, which suggests that some children may find the concept of using humor at your own expect hard to grasp. It may therefore have been more difficult to develop simplified items to represent a humor style which may be less familiar to 
children. As Martin et al. (2003) highlighted, self-defeating humor can affect one’s relationships. For example, children may tire of those who regularly use self-defeating humor, feeling they need to provide constant reassurance which may cause fractions in their friendships (see James and Fox 2016). In addition, frequently drawing attention to their weaknesses in order to amuse others may result in children becoming increasingly focused on their flaws. This reinforcement of negative cognitions may in turn have a negative effect on a child’s emotional health.

Kuiper et al. (2010) were interested in co-variation patterns between the four humor styles. In study three, affiliative humor was found to be related to the use of all other styles of humor. The finding that negative styles of humor may be used alongside the more positive styles provides further evidence of the need to influence children's understanding of the potential consequences of their humor use. As Martin et al. (2013) stated the absence of detrimental uses of humor may be just as important as the presence of positive uses. These overlaps also highlight the need to look for 'humor types' in younger children, to recognise that children (like adults) may use combinations of humor styles, which may be differentially associated with adjustment (Fox et al. 2016; Galloway 2010; Leist and Müller 2013).

In support of both Martin et al. (2003) and Fox et al. (2013), significant gender differences also became apparent from study three, where boys were found to use a greater amount of both maladaptive humor styles. As stated by Martin et al. (2003), it is unsurprising that males have a greater tendency to use aggressive humor; it is less clear however, why males may be more likely to use self-defeating humor. It therefore seems that interventions aimed at tackling less positive uses of humor may be particularly beneficial for males. In contrast to gender differences, year group differences were less notable. For example in study three, no significant differences were found for the four humor styles. This suggests that by age eight or nine, children may be using all four humor styles and that significant age 
differences in the use of particular humor styles may not occur for the remaining years at primary school. It should also be noted that if some children are using all four humor styles by the age of eight, there may be a need to explore the presence of different styles of humor in children at an even younger age.

In terms of advantages of the current work, including both self and peer reports of humor provided multiple informants and an insider perspective. Concerns had been raised surrounding children's ability to self-report their own humor use. For example, children may be more reluctant to admit to using negative forms of humor, most notably aggressive, or may report greater use of positive styles of humor. Allport (1961) for instance, found that when asked about their own humor abilities, the majority of respondents considered themselves to have an average or above average sense of humor. As agreement was found between self and peer reports of affiliative, aggressive and self-defeating humor, it seems that children are in fact reasonable reporters of their own humor use, which provides further validation for the HSQ-Y as a measure. For self-enhancing humor, the correlation between peer and self-reports was not significant. It may nonetheless be problematic for peers to report on self-enhancing humor due to the nature of this humor style and its use as an internal coping method.

Although the studies provide evidence of associations between humor and psychosocial adjustment, due to their cross sectional nature, cause and effect cannot be determined. Whilst use of a maladaptive humor style may lead to poor adjustment and use of an adaptive humor style to better adjustment, it could work both ways. For example, a welladjusted child who is accepted by their peers may be provided with more opportunities to practice using positive humor styles. A child who is rejected by their peers on the other hand, may have decreased opportunities and resort to using less positive forms of humor. Longitudinal work is now being conducted and it is hoped that this will address the 
unanswered questions regarding the direction of causality. Future work should consider how children's awareness surrounding the four styles of humor and their potential positive and negative outcomes can be raised.

\section{References}

Allport, Gordon W. 1961. Pattern and growth in personality. New York: Holt, Rinehart \& Winston.

Altshuler, Jennifer T. \& Diane N. Ruble. 1983. Developmental changes in children's awareness of strategies for coping with uncontrollable stress. Child Development 60.1337-1349.

Asher, Steven R., Shelley Hymel \& Peter D. Henshaw. 1984. Loneliness in children. Child Development 55. 1456-1464.

Bentler, Peter M. 1992. On the fit of models to covariances and methodology to the Bulletin. Psychological Bulletin 112. 400-404.

Bergen, Doris. 2007. Development of a sense of humor. In Willibald Ruch (ed.), The sense of humor: Exploration of a personality characteristic, 329-358. Berlin: Mouton De Gruyter

Borgers, Natacha, Joop Hox \& Dirk Sikkel. 2004. Response effects in surveys in children and adolescents: The effect of number of response options, negative wording and neutral mid-point. Quality and Quantity 38. 17-33.

Bukowski, William M., Betsy Hoza \& Michel Boivin. 1994. Measuring friendship quality during pre- and early adolescence: The development and psychometric properties of the friendship qualities scale. Journal of Social and Personal Relationships 11. 471-484.

Damico, Sandra B. \& William W. Purkey. 1978. Class clowns: A study of middle school students. American Educational Research Journal 15. 391-385. 
Dowling, Jacqueline S. \& James A. Fain. 1999. A multidimensional sense of humor scale for school-aged children: Issues of reliability and validity. Journal of paediatric Nursing 14. 38-43.

Erickson, Sarah J. \& Sarah W. Feldstein. 2007. Adolescent humor and its relationships to coping, defense strategies, psychological distress and well-being. Child Psychiatry and Human Development 37. 255-271

Fabrizi, Michael S. \& Howard R. Pollio. 1987. A naturalistic study of humorous activity in a third, seventh, and eleventh grade classroom. Merrill-Palmer Quarterly 33. 107-128.

Fitts, Sherri D., Rickard A Sebby \& Martha S Zlokovich. 2009. Humor styles as mediators of the shyness-loneliness relationship. North American Journal of Psychology 11. 257272.

Fox, Claire L., Sarah Dean \& Kerri Lyford. 2013. Development of a humor styles questionnaire for children. Humor: International Journal of Humor Research 26. 295319.

Fox, Claire L., Simon C. Hunter \& Siân Emily Jones. 2015. Reciprocity between Humor Styles and Psychosocial Adjustment in Children. Manuscript in preparation.

Fox, Claire L., Simon C. Hunter \& Siân Emily Jones. 2016. Associations between humor types in children and their psychosocial adjustment. Personality and Individual Differences 89. 86-91.

Freiheit, Stacy R, James C. Overholser \& Kim L. Lehnert. 1998. The association between humor and depression in adolescent psychiatric inpatients and high school students. Journal of Adolescent Research 12. 32-48.

Führ, Martin. 2002. Coping humor in early adolescence. Humor: International Journal of Humor Research 15. 283-304. 
Galloway, Graeme. 2010. Individual differences in personal humor styles: Identification of prominent patterns and their associates. Personality and Individual Differences 48. 563567.

Goodenough, Belinda \& Jennifer Ford. 2005. Self-reported use of humor by hospitalized preadolescent children to cope with pain-related distress from a medical intervention. Humor: International Journal of Humor Research 18. 279-298.

Harter, Susan. 1985. Manual for the self-perception profile for children. Denver: Denver University Press.

Hu, Litze T. \& Peter M. Bentler. 1999. Cut-off criteria for fit indexes in covariance structure analysis: Conventional criteria versus new alternatives. Structural Equation Modelling 6. 1-55.

James, Lucy A. \& Claire L. Fox. 2016. Children’s understanding of self-focused humor styles. Europe’s Journal of Psychology 12. 420-433.

Jones, Siân Emily, Claire Fox, Hayley Gilman, Lucy James, Toni Karic, Katie WrightBevans \& Victoria Caines. 2013. 'I’m being called names and I'm being hit'. The challenges of longitudinal research on bullying amongst 11-13-years-olds. Pastoral care in education 31. 321-336.

Klein, Dana N. \& Nicholas A. Kuiper. 2006. Humor styles, peer relationships and bullying in middle childhood. Humor: International Journal of Humor Research 19. 383-404.

Kuiper, Nicholas A., Melissa Grimshaw, Catherine Leite \& Gillian A. Kirsh. 2004. Humor is not always the best medicine: Specific components of sense of humor and psychological well-being. Humor: International journal of Humor Research 17. 135168. 
Kuiper, Nicholas A., Gillan A. Kirsh \& Catherine Leite. 2010. Reactions to humorous comments and implicit theories of humor styles. Europe's Journal of Psychology 3. 236-266.

Leist, Anja K. \& Daniela Müller. 2013. Humor types show different patterns of selfregulation, self-esteem and well-being. Journal of Happiness Studies 14. 551-569.

Marsh, Herbert W. 1986. Negative item bias in ratings scales for preadolescent children: A cognitive-developmental phenomenon. Developmental Psychology 22. 37-49.

Martin, Rod A. 2007. The psychology of humor: An integrative approach. Burlington, MA: Elsevier Academic Press.

Martin, Rod A. \& Herbert M. Lefcourt. 1983. Sense of humor as a moderator of the relation between Stressors and moods. Journal of Personality and Social Psychology 45. 13131324.

Martin, Rod A., Patricia Puhlik-Doris, Gwen Larsen, Jeanette Gray \& Kelly Weir. 2003. Individual differences in use of humor and their relation to psychological well-being: Development of the Humor Styles Questionnaire. Journal of Research in Personality 37. 48-75.

Masten, Ann S. 1986. Humor and social competence in school-aged children. Child Development 57. 461-473.

McGhee, Paul E. 1974. Cognitive mastery and children's humor. Psychological Bulletin 81. 721-730.

Nolen-Hoeksema, Susan, Joan S. Girgus \& Martin E. P. Seligman. 1991. Sex differences in depression and explanatory style in children. Journal of Youth and Adolescence 20. 233-245. 
Parker, Jeffrey G. \& Steven R. Asher. 1993. Friendship and friendship quality in middle childhood: Links with peer group acceptance and feelings of loneliness and social dissatisfaction. Developmental Psychology 29. 611-621.

Portney, Leslie G. \& Mary P. Watkins. 2000. Foundations of clinical research: Applications to practice $2^{\text {nd }}$ ed. Highland Park, NJ: Hall Health.

Poulin, François \& Thomas J. Dishion. 2008. Methodological issues in the use of sociometric assessment with middle school youth. Social Development 17. 908-921.

Rotenberg, Kenneth J., Michael J Boulton \& Claire L. Fox. 2005. Cross-sectional and longitudinal relations among children’s trust beliefs, psychological maladjustment and social relationships: Are very high as well as very low trusting children at risk? Journal of Abnormal Child Psychology 33. 595-610.

Sherman, Lawrence W. 1988. Humor and social distance in elementary school children. Humor: International Journal of Humor Research 1. 389-404.

Singleton, Louise C. \& Steven R. Asher. 1977. Peer preferences and social interaction among third-grade children in an integrated school district. Journal of Educational Psychology 69. 330-336.

Sletta, Olav, Frode Søbstad \& Harald Valås. 1995. Humor, peer acceptance and perceived social competence in preschool and school-aged children. British Journal of Educational Psychology 65. 179-195.

Sprecher, Susan \& Pamela C. Regan. 2002. Liking some things (in some people) more than others: Partner preferences in romantic relationships and friendships. Journal of Personal and Social Relationships 19. 463-481.

Tucker, Raymond P., LaRicka R. Wingate, Victoria M. O’Keefe, Meredith L. Slish, Matt R. Judah \& Sarah Rhoades-Kerswill. 2013. The moderating effect of humor style on the 
relationship between interpersonal predictors of suicide and suicidal ideation. Personality and Individual Differences 54. 610-615.

Vernon, Philip A., Rod A. Martin, Julie A. Schermer \& Ashley Mackie. 2008. A behavioural genetic investigation of humor styles and their correlations with the Big-5 personality dimensions. Personality and Individual Differences 44, 1116-1125.

Warnars-Kleverlaan, Nel, Louis Oppenheimer \& Larry Sherman. 1996. To be or not to be humorous: Does it make a difference. Humor: International Journal of Humor Research 9. 117-141.

Yip, Jeremy A. \& Rd A. Martin. 2006. Sense of humor, emotional intelligence and social competence. Journal of Research in Personality 40. 1202-1208. 


\section{Table 1}

Factor loadings using the rotated solution for the 14 HSQ-Y items $(N=250)$

\begin{tabular}{|c|c|c|c|}
\hline & Mean (SD) & Agg & Aff \\
\hline $\begin{array}{l}\text { Agg5 'When I think of something that is funny about someone, I say it, even if it gets me } \\
\text { into trouble' }\end{array}$ & $1.81(1.01)$ & .80 & \\
\hline Agg6 'I find it funny when people laugh at someone to make them look silly' & $1.83(.97)$ & .78 & \\
\hline Agg3 'When I tell jokes I do not think about who I might upset' & $1.90(.92)$ & .74 & \\
\hline Agg7 'I sometimes laugh at other people if my friends are too' & $2.43(1.07)$ & .72 & \\
\hline Agg8 'If I don’t like someone, I make fun of them' & $1.63(.86)$ & .72 & \\
\hline Agg2 'When something is really funny, I will laugh about it even if it will upset someone' & $1.99(.93)$ & .72 & \\
\hline Agg4 ‘When other people are laughing at someone I will join in’ & $2.01(1.01)$ & .67 & \\
\hline Aff5 'People often laugh at the funny things I say' & $3.30(.78)$ & & .83 \\
\hline Aff4 'I am a funny person’ & $3.44(.71)$ & & .80 \\
\hline Aff7 'I find it easy to make people laugh' & $3.31(.80)$ & & .79 \\
\hline Aff1 'I can be funny without having to try very hard' & $3.14(.69)$ & & .65 \\
\hline Aff2 'My jokes and funny stories make people laugh' & $3.25(.77)$ & & .65 \\
\hline Aff3 'It is easy for me to think of funny things to say when I am with other children' & $3.31(.78)$ & & .63 \\
\hline Aff6 'I can make my friends and family laugh' & $3.68(.54)$ & & .62 \\
\hline$\%$ of variance explained & & 28.40 & 24.68 \\
\hline Eigenvalue & & 3.98 & 3.46 \\
\hline
\end{tabular}

Only factor loadings greater than .3 presented. Aff is affiliative, Agg is aggressive 
Table 2

Cronbach's alphas for individual subscales ( $n$ in brackets)

\begin{tabular}{lll}
\hline Subscales & Original & Revised \\
\hline Affiliative & $.89(167)$ & .88 (affiliative6 deleted) \\
Aggressive & $.86(154)$ & .84 (aggressive7 deleted) \\
Self-enhancing & $.71(158)$ & .71 \\
Self-defeating & $.61(156)$ & .62 (self-defeating5,6 deleted) \\
\hline
\end{tabular}




\section{Table 3}

Factor loadings using the rotated solution for the 22 HSQ-Y items $(N=161)$

\begin{tabular}{|c|c|c|c|c|c|}
\hline & Mean (SD) & Aff & Agg & Se & Sd \\
\hline Aff7 'I find it easy to make people laugh & $3.10(1.03)$ & .87 & & & \\
\hline Aff4 'I am a funny person' & $3.29(.94)$ & .82 & & & \\
\hline Aff2 ‘My jokes and funny stories make people laugh’ & $3.00(1.05)$ & .81 & & & \\
\hline Aff5 'People often laugh at the funny things I say' & $3.25(.88)$ & .75 & & & \\
\hline $\begin{array}{l}\text { Aff3 'It is easy for me to think of funny things to say when I am with } \\
\text { other children' }\end{array}$ & $3.18(1.03)$ & .72 & & & \\
\hline Aff1 'I can be funny without having to try very hard' & $3.10(.85)$ & .65 & & & \\
\hline $\begin{array}{l}\text { Agg5 'I find it funny when people laugh at someone to make them } \\
\text { look silly' }\end{array}$ & $2.22(1.11)$ & & .82 & & \\
\hline $\begin{array}{l}\text { Agg3 'When something is really funny, I will laugh about it even if it } \\
\text { will upset someone' }\end{array}$ & $2.01(1.02)$ & & .79 & & \\
\hline $\begin{array}{l}\text { Agg2 'When I think of something that is funny about someone, I say } \\
\text { it, even if it gets me into trouble' }\end{array}$ & $2.00(1.02)$ & & .74 & & \\
\hline Agg4 'When I tell jokes, I do not think about who I might upset' & $2.11(1.05)$ & & .72 & & \\
\hline Agg6 'I sometimes laugh at other people if my friends are too' & $2.60(1.01)$ & & .68 & & .31 \\
\hline Agg1 'When other people are laughing at someone, I will join in' & $2.49(1.09)$ & & .62 & & \\
\hline $\begin{array}{l}\text { Se4 'Even if I am feeling angry or upset, I can still find something to } \\
\text { laugh about' }\end{array}$ & $2.96(1.09)$ & & & .75 & \\
\hline $\begin{array}{l}\text { Se1 'When I am feeling sad, I think of something funny to cheer } \\
\text { myself up' }\end{array}$ & $2.96(1.12)$ & & & .73 & \\
\hline Se2 'If I am feeling worried, it helps to think of something funny' & $2.58(1.12)$ & & & .68 & \\
\hline Se3 'If something is difficult, it helps to find something funny about it' & $2.53(1.03)$ & & & .58 & \\
\hline Se5 'I can find things to laugh about when I am on my own' & $3.05(.99)$ & & & .47 & \\
\hline Se6 'Being a funny person stops me from being sad' & $2.99(.98)$ & .40 & & .44 & \\
\hline Sd3 'Making fun of myself makes other people laugh' & $2.70(1.14)$ & & & & .73 \\
\hline Sd1 'I let other people laugh or joke about me more than I should' & $2.37(1.07)$ & & & & .67 \\
\hline Sd4 'Letting others laugh at me is a good way to make friends' & $2.38(1.11)$ & & & & .64 \\
\hline Sd2 'I am often the person that others are laughing at' & $2.53(1.07)$ & & & & .61 \\
\hline$\%$ of variance explained & & 22.50 & 15.75 & 10.06 & 6.59 \\
\hline Eigenvalue & & 4.95 & 3.47 & 2.21 & 1.45 \\
\hline
\end{tabular}

Only factor loadings greater than .3 presented. Aff is affiliative, Agg is aggressive, Se is self-enhancing, Sd is self-defeating 
Table 4

Intercorrelations between measures

$\begin{array}{lllll}\text { Affiliative Aggressive } & \begin{array}{l}\text { Self- } \\ \text { enhancing }\end{array} & \begin{array}{l}\text { Self- } \\ \text { defeating }\end{array} & \text { Closeness } & \text { Conflict } \\ & & & \end{array}$

\begin{tabular}{llllll}
\hline Affiliative & -- & & & & \\
Aggressive & $.25^{* *}$ & -- & & \\
Self-enhancing & $.35^{* * *}$ & -.08 & -- & & \\
Self-defeating & $.18^{*}$ & $.21^{* *}$ & $.24^{* *}$ & -- & - \\
Closeness & .02 & $-.18^{*}$ & .15 & -.05 & - \\
Conflict & -.02 & $.27^{* * *}$ & $-.16^{*}$ & $.21^{* *}$ & $-.36^{* * *}$ \\
\hline$* p<.05,{ }^{* *} p<.01,{ }^{* *} p<.001$ & & & & -
\end{tabular}




\section{Table 5}

Factor loadings using the rotated solution for the 24 HSQ-Y items $(N=225)$

\begin{tabular}{|c|c|c|c|c|c|}
\hline & Mean (SD) & Aff & Agg & Se & Sd \\
\hline Aff6 'I find it easy to make people laugh' & $3.05(.89)$ & .88 & & & \\
\hline Aff4 'I am a funny person' & $3.21(.83)$ & .82 & & & \\
\hline Aff5 'People often laugh at the funny things I say’ & $3.09(.87)$ & .81 & & & \\
\hline Aff2 'My jokes and funny stories make people laugh’ & $3.11(.87)$ & .74 & & .30 & \\
\hline Aff3 'It is easy for me to think of funny things to say when I am with other children' & $3.02(.83)$ & .74 & & & \\
\hline Aff1 'I can be funny without having to try very hard' & $3.00(.76)$ & .70 & & & \\
\hline Agg3 'When something is really funny, I will say it even if it might upset someone' & $1.99(.92)$ & & .78 & & \\
\hline Agg4 'When I tell jokes, I do not think about who I might upset' & $1.88(.85)$ & & .77 & & \\
\hline Agg5 'I find it funny when people laugh at someone to make them look silly' & $1.79(.94)$ & & .75 & & \\
\hline $\begin{array}{l}\text { Agg2 'When I think of something that is funny about someone, I say it, even if it gets me } \\
\text { into trouble' }\end{array}$ & $1.93(.94)$ & & .72 & & \\
\hline Agg6 'I sometimes laugh at other people if my friends are too' & $2.28(.93)$ & & .67 & & \\
\hline Agg1 'When other people are laughing at someone, I will join in' & $2.14(.96)$ & & .67 & & \\
\hline Se1 'When I am feeling sad, I think of something funny to cheer myself up' & $2.90(1.06)$ & & & .78 & \\
\hline Se2 'If I am feeling worried, it helps to think of something funny' & $2.53(.99)$ & & & .75 & \\
\hline Se4 'Even if I am feeling angry or upset, I can still find something to laugh about' & $2.83(1.02)$ & & .31 & .65 & \\
\hline Se3 'If something is difficult, it helps to find something funny about it' & $2.37(.94)$ & & & .65 & \\
\hline Se5 'I can find things to laugh about when I am on my own' & $2.80(1.01)$ & & & .52 & \\
\hline Se6 'Being a funny person stops me from being sad' & $2.78(1.02)$ & & .47 & .48 & \\
\hline Sd6 'At times, I make jokes about myself when I am with others a bit too much' & $2.24(.97)$ & & & & .75 \\
\hline Sd3 'Making fun of myself makes other people laugh' & $2.47(1.08)$ & & & & .71 \\
\hline Sd1 'I let other children laugh or joke about me more than I should' & $2.36(.91)$ & & & & .62 \\
\hline Sd5 'I can find things to laugh about when I am on my own' & $2.71(.99)$ & & & & 61 \\
\hline Sd4 'Letting others laugh at me is a good way to make friends' & $2.08(.99)$ & & & & .58 \\
\hline Sd2 'I am often the person that others are laughing at' & $2.36(.94)$ & & & & .34 \\
\hline$\%$ of variance explained & & 24.28 & 15.81 & 8.14 & 6.31 \\
\hline Eigenvalue & & 5.83 & 3.80 & 1.96 & 1.51 \\
\hline
\end{tabular}

Only factor loadings greater than .3 presented. Aff is affiliative, Agg is aggressive, Se is self-enhancing, Sd is self-defeating 
Table 6

Factor loadings from confirmatory factor analysis

\begin{tabular}{llllllll}
\hline Affiliative & $\begin{array}{l}\text { Factor } \\
\text { loadings }\end{array}$ & Aggressive & $\begin{array}{l}\text { Factor } \\
\text { loadings }\end{array}$ & $\begin{array}{l}\text { Self- } \\
\text { enhancing }\end{array}$ & $\begin{array}{l}\text { Factor } \\
\text { loadings }\end{array}$ & $\begin{array}{l}\text { Self- } \\
\text { defeating }\end{array}$ & $\begin{array}{l}\text { Factor } \\
\text { loadings }\end{array}$ \\
\hline Aff1 & .62 & Agg1 & .56 & SEn1 & .66 & SD1 & .48 \\
Aff2 & .78 & Agg2 & .70 & SEn2 & .64 & SD2 & .23 \\
Aff3 & .76 & Agg3 & .75 & SEn3 & .50 & SD3 & .72 \\
Aff4 & .79 & Agg4 & .73 & SEn4 & .68 & SD4 & .49 \\
Aff5 & .79 & Agg5 & .73 & SEn5 & .53 & SD5 & .50 \\
Aff6 & .89 & Agg6 & .63 & SEn6 & .64 & SD6 & .75 \\
\hline Affic
\end{tabular}

Aff is affiliative, Agg is aggressive, SEn is self-enhancing, SD is self-defeating, 
Table 7

Intercorrelations between measures

\begin{tabular}{|c|c|c|c|c|c|c|c|c|c|}
\hline & AFF & AGG & SEN & SD & $\mathrm{LON}$ & GSW & SPSC & FRI & $\mathrm{PA}$ \\
\hline \multicolumn{10}{|l|}{ Aff } \\
\hline Agg & $.15^{*}$ & -- & & & & & & & \\
\hline SEN & $.50 * * *$ & -.01 & -- & & & & & & \\
\hline SD & $.20 * *$ & $.36 * * *$ & $.22 * *$ & -- & & & & & \\
\hline LON & $-.24 * * *$ & .04 & $-.28 * * *$ & .07 & -- & & & & \\
\hline GSW & $.21^{* *}$ & -.07 & $.31 * * *$ & -.01 & $-.46 * * *$ & -- & & & \\
\hline SPSC & $.24 * *$ & $.17^{*}$ & $.24 * *$ & .09 & $-.53 * * *$ & $.50 * * *$ & -- & & \\
\hline FRI & $.25^{* * *}$ & -.02 & .14 & -.01 & $-.32 * * *$ & .06 & $.15^{*}$ & -- & \\
\hline PA & $.29 * * *$ & -.12 & $.21^{* *}$ & -.01 & $-.39 * * *$ & .11 & $.24^{* *}$ & $.41 * * *$ & -- \\
\hline
\end{tabular}

${ }^{*} p<.05, * * p<.01, * * * p<.001$

AFF is affiliative, AGG is aggressive, SEN is self-enhancing, SD is self-defeating, Lon is loneliness, GSW is Global self-worth, SPSC is self-perceived social competence, Fri is Mutual Friends, PA is Peer Acceptance 
Table 8

Means (and SDs) for Males and Females and year groups for the HSQ-Y subscales

\begin{tabular}{|c|c|c|c|c|c|}
\hline & Year4 & Year5 & Year6 & Overall & $F$ values \\
\hline \multicolumn{6}{|c|}{ Affiliative } \\
\hline Males & $2.98(.87)$ & $3.17(.70)$ & $4.00(.56)$ & 3.09 (.69) & $G F(1,157)=.13$ \\
\hline Females & 3.08 (.68) & $2.84(.80)$ & $3.21(.49)$ & $3.06(.67)$ & YG $F(2,157)=.77$ \\
\hline Overall & $3.04(.76)$ & $3.03(.75)$ & $3.15(.53)$ & 3.08 (.68) & GxYG $F(2,157)=1.63$ \\
\hline \multicolumn{6}{|c|}{ Aggressive } \\
\hline Males & $2.11(.67)$ & $2.15(.74)$ & $2.25(.76)$ & $2.18(.73)^{\mathrm{a}}$ & $G F(1,157)=17 \cdot 12^{* * *}$ \\
\hline Females & $1.78(.64)$ & $1.48(.42)$ & $1.96(.55)$ & $1.76(.58)^{\mathrm{a}}$ & YG $F(2,157)=2.65$ \\
\hline Overall & $1.92(.67)$ & $1.86(.70)$ & 2.12 (.69) & 1.98 (.69) & GxYG $F(2,157)=1.25$ \\
\hline \multicolumn{6}{|c|}{ Self-enhancing } \\
\hline Males & $2.51(.79)^{\mathrm{c}}$ & $2.94(.72)$ & $2.66(.65)$ & $2.70(.72)$ & $G F(1,157)=.25$ \\
\hline Females & $2.93(.61)^{\mathrm{c}}$ & $2.55(.65)$ & $2.78(.58)$ & $2.78(.62)$ & YG $F(2,157)=.02$ \\
\hline Overall & $2.76(.71)$ & $2.77(.71)$ & $2.71(.62)$ & $2.74(.67)$ & GxYG $F(2,157)=4.55^{*}$ \\
\hline \multicolumn{6}{|c|}{ Self-defeating } \\
\hline Males & $2.46(.66)$ & $2.37(.72)$ & $2.60(.66)$ & $2.49(.68)^{b}$ & $G F(1,157)=5.15^{*}$ \\
\hline Females & 2.29 (.69) & $2.08(.55)$ & $2.38(.47)$ & $2.26(.59)^{\mathrm{b}}$ & YG $F(2,157)=2.23$ \\
\hline Overall & $2.36(.68)$ & $2.24(.66)$ & $2.50(.59)$ & $2.38(.65)$ & GxYG $F(2,157)=.11$ \\
\hline
\end{tabular}

$n=116$ males, 109 females (year $4=75$, year $5=68$, year $6=82$ ) $G=$ Gender and YG = Year Group Means in a row or column sharing a superscript are significantly different 